\title{
Test methods for grease of shield tail seal in shield engineering Song Fangjia ${ }^{1,}$, Wang Yongwei ${ }^{1, b}$, Wang Jinming ${ }^{1, c}$, Zhang Jie ${ }^{1, d}$, Yang Maoqian ${ }^{1, \mathrm{e}}$ \\ ${ }^{1}$ Shandong Academy of Building Research, Jinan 250031, China

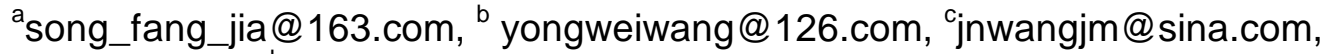 djessiezjie@163.com, ${ }^{\mathrm{e}}$ yangmaoqian@126.com
}

\begin{abstract}
Keywords: Test methods, Grease of shield tail seal, Shield engineering
Abstract. Shield tail grease is very important to the tightness and durability of shield tail structure, and the consumption is very large as well as the construction has been accelerated. At present the related indexes of shield tail seal grease has no uniform standards, in the actual construction process for shield tail seal grease selection and testing still has certain blindness and subjectivity, is not conducive to the application of shield construction, contrary to the concept of energy saving and environmental protection. This study combined with the actual situation of domestic construction, the main technical indexes of the shield tail seal grease are summarized and elaborated the corresponding test methods, test speed and accuracy of the test of shield tail seal grease can effectively improve ,to avoid unnecessary waste.
\end{abstract}

\section{Introduction}

In recent years, with the expansion of the scale of cities in China, the backwardness of infrastructure and the problems of urban transportation have become increasingly prominent. With its advantages of safety, punctuality and speed, the subway plays a more and more important role in expanding urban space, building urban rapid three-dimensional transportation network and improving the urban traffic environment. By June 2017, subway had been constructed and put into operation in 29 cities of China. According to the current construction speed of 100 120 kilometers per year, the construction of urban rail transit line will reach 2000 2500 km by 2020 .

In the construction of metro, shield construction is selected as the first choice in urban construction due to its advantages of high efficiency, safety, stability and low strength. However, in order to ensure the safety and reliability of the subway project, the construction of the shield will use and consume a large amount of energy and materials. Shield tail grease is one of main supporting materials for those with steel wire type shield tail, and can effectively protect the shield tail and cut off the slurry. So it can guarantee the smooth progress of the shield, reduce the corrosion and abrasion of shield.

At present, there is no systematic standard for the testing of this kind of grease at home and abroad, and there are great differences between different enterprises, which is not conducive to the test, selection and application of construction enterprises. This study made a systematic study on the shield tail seal grease, in the full understanding of the current basic testing method for the product characteristics of shield tail seal grease and related indicators, screening and summarizes testing method of shield tail seal grease which are suitable for the shield construction in China; and the problems needing attention in the process of test and application are summarized, which can reduce the blindness in the construction process, improve the testing speed and accuracy of the grease of the shield tail grease, and avoid unnecessary waste.

\section{Brief introduction to shield engineering and shield tail seal grease}

\section{Brief introduction of shield machine}

Shield tunneling method is a fully mechanized construction method in underground excavation. It is to push the shield machine into the ground, through the shield casing and segments supporting 
surrounding rock, to prevent the collapse into the tunnel. At the same time in front of the excavation face cutting device for sgrease excavation, unearthed by machinery shipped outside, by jack in the back pressure jacking, and assembling precast concrete segments. After the segment of the shield is assembled, the synchronous grouting is used to fill the cavity between the shield segment and the sgrease to maintain the stability of the sgrease. The tail of the shield machine needs to be sealed by shield tail brush and shield tail grease.

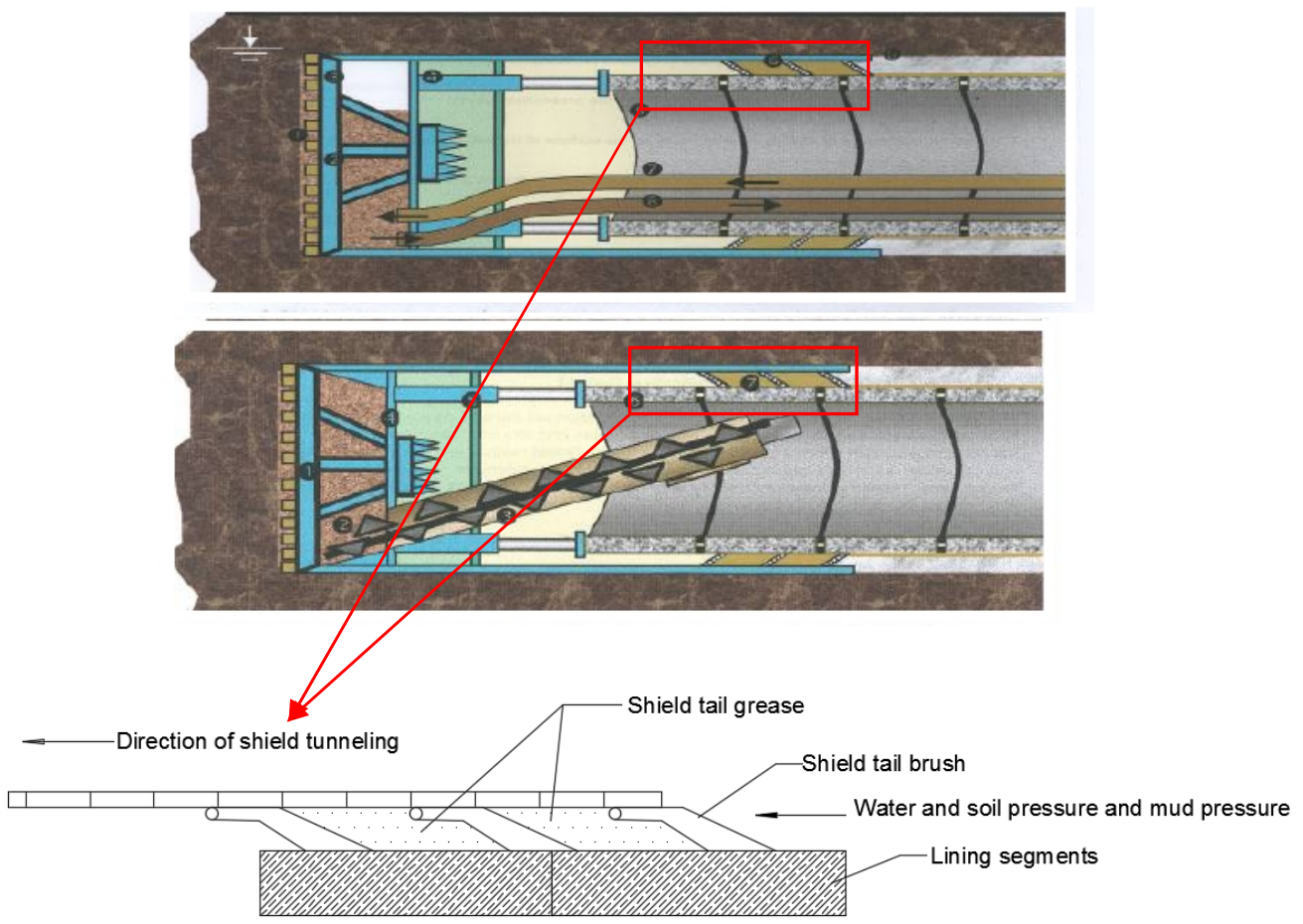

Fig.1 Shield machine and shield tail detail structure

\section{Brief introduction of shield tail grease}

Between the inner surface of the shield tail and the outer surface of lining segment, set the shield tail sealing device, to prevent water and slurry leaking into the TBM, also can keep the grouting pressure (about $0.3 \sim 0.5 \mathrm{MPa}$ ) during the synchronous grouting or follow grouting in the gap between the out surface of the surrounding rock and the outer surface of lining segment.

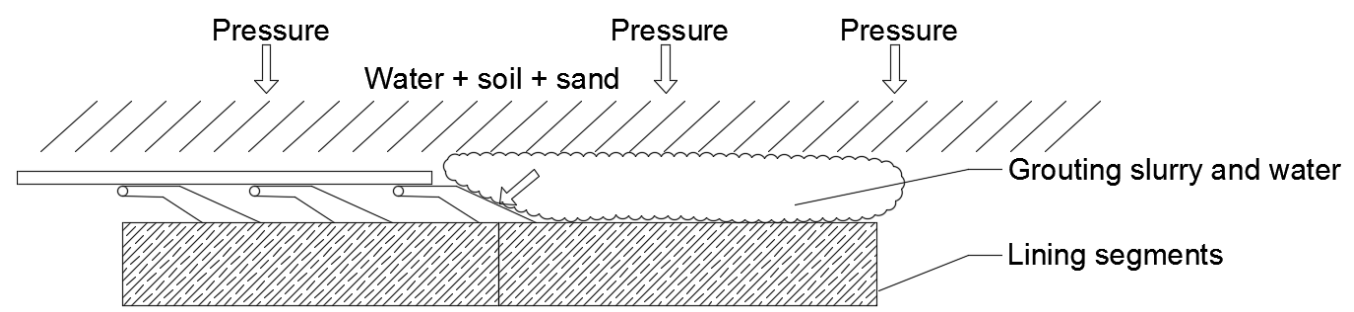

Fig.2 Schematic diagram of sealing water for sealing grease of shield

Before the shield machine enters the field, the worker will welds three or more brushes in the design position according to the design request. 


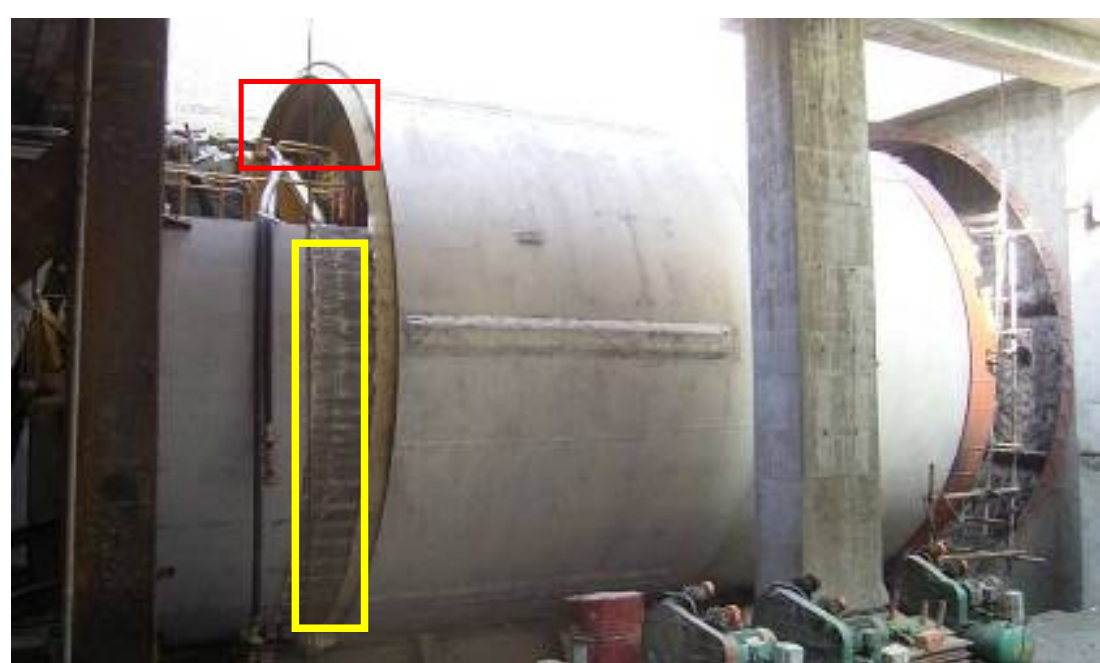

Fig.3 Shield tail three shield tail brush (red frame) and shield tail grease (yellow frame)

\section{The types of grease in the tail shield}

Shield sealing grease is divided into two kinds: shield tail grease and shield tail brush grease.

1. The sheild tail grease is through the shield injection system, injected into the cavity surrounded by shield tail brush. With the continuous advance of the shield, the grease at the end of the shield will be attached to the outer wall of the shield segment to play the role of lubrication and sealing. In addition, the two cavities will keep the dynamic pressure balance under the control of the computer, so as to prevent the slurry of the synchronous grouting of the shield tail from breaking through the shield tail brush and enter the shield machine.

2. Shield tail brush protection grease is in the shield approach, the workers hand painted to brush tail brush between the steel wire, thus playing the role of water seal and shield tail brush. Therefore, it is more viscous and difficult to break through slurry.

Table 1 The contrast of two kinds of seal grease

\begin{tabular}{|c|c|c|}
\hline & TAIL GREASE & $\begin{array}{l}\text { SHIELD TAIL BRUSH PROTECTS } \\
\text { GREASE }\end{array}$ \\
\hline TYPE & consumables & Disposable \\
\hline INJECTION FORM & Automatic injection & Hand painting \\
\hline LOCATION & $\begin{array}{l}\text { Cavity formed by shield tail } \\
\text { brush }\end{array}$ & $\begin{array}{c}\text { The inside of the steel wire of the shield tail } \\
\text { brush }\end{array}$ \\
\hline CONSUMPTION & $25 \sim 30 \mathrm{t} / \mathrm{km}$ & $0.7 \sim 0.8 \mathrm{t}$ \\
\hline FUNCTION & $\begin{array}{l}\text { Lubrication, water stop, } \\
\text { shield machine }\end{array}$ & Protect shield tail brush, stop water \\
\hline PENETRATION & $(230 \pm 10) \mathrm{mm}$ & $(205 \pm 5) \mathrm{mm}$ \\
\hline $\begin{array}{l}\text { TECHNICAL } \\
\text { REQUIREMENT }\end{array}$ & Good pumping and viscosity & Higher viscosity, no pumping required \\
\hline
\end{tabular}

\section{Main technical indexes and testing methods}

\section{Technical index}

There are three main indexes of the shield tail grease, namely pumping, viscosity index and specific gravity.

\section{Pumping}

Since the shield tail grease is a product that needs to be transported to the shield cavity of the shield machine, a good pumping performance is one of the main features of the product. The good pumping performance is mainly determined by the length of fiber in the product. Too long fiber can cause pumping difficulties, and cause damage to the shield tail grease pump, suitable for fiber length and density to ensure a moderate grease can normal delivery to the grease cavity. 


\section{viscosity index}

Excellent adhesion is an important guarantee to ensure that the shield machine will not leak, and the grease can only be properly adhered to the shield tail brush. High viscous base grease enhances the adhesion between the shield and the tail brush and sealing surface of the shield. It is an important guarantee for the product to prevent water and slurry, and does not affect the pumping performance of the product.

\section{specific gravity}

The specific gravity is the density of the product. The consumption of the tail grease is calculated by volume, and the smaller the specific gravity, the less it consumes. The special water resistant composite packing ensures the water resistance of the shield grease. The proper density has great influence on the waterproof and consumption of the product.

\section{Testing methods}

\section{Pumping test}

Pumping is mainly measured by penetration of grease. In accordance with the standard (GB/T4509 petroleum asphalt penetration test) requirements, the sample temperature should be 25 degrees, for penetration of more than 200 (unit $0.1 \mathrm{~mm}$ ) of the sample.

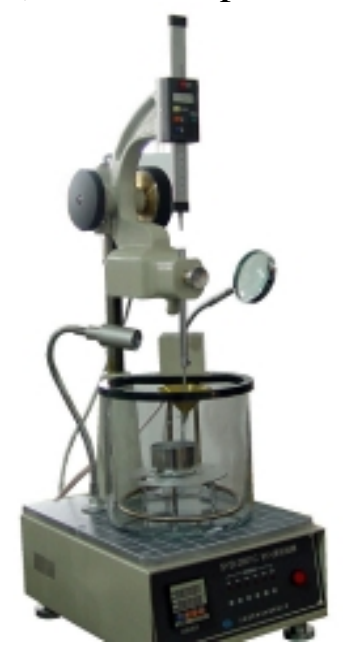

Fig.4 Penetration tester for asphalt grease

\section{Test procedure:}

1. Take out the sample dish that reaches a constant temperature, and move into a tripod on the bottom of the test glass in the test temperature. The depth of the water above the sample surface is not less than $10 \mathrm{~mm}$.

2. Place the sample glass pan on the platform of penetrometer. Unscrew the fastening screws at the rear of the elevator. Move the lifting frame up and down to the right place. Then use both sides to trim the handwheel, slowly put down the needle connecting rod, use the mirror to observe, so that the needle just touch the surface of the sample, let go, and the lifting frame is self-locking.

3. Press the reset button on the display panel.

4. After setting zero 5S, press the start button. The standard needle drops into the sample and reads the displacement indicator reading.

5. Parallel trials of the same specimen were performed at least 3 times, and the distance between each test point and the edge of the sample tray shall not be less than $10 \mathrm{~mm}$. Each test should be replaced with a clean standard needle, or standard needle, and dried with cotton or cotton dipped in trichloroethylene solvent.

\section{Viscosity index test}

Water resistance and tightness 


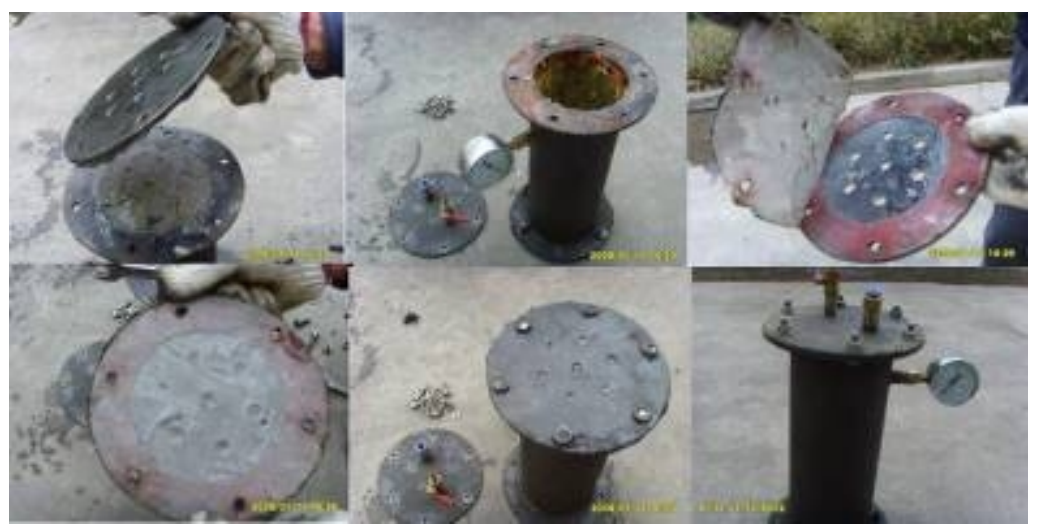

Fig.5 Diagram of pressure seal test device

\section{Test procedure:}

1. Place the shield grease at the bottom of the container, about $4 \mathrm{~cm}$;

2. Load the water above the container;

3. Cover well, seal well, add air pressure to $0.8 \mathrm{MPa}$;

4. Observe the pressure gauge and the leakage of grease or water at the bottom of the container. Record the the leakage time.

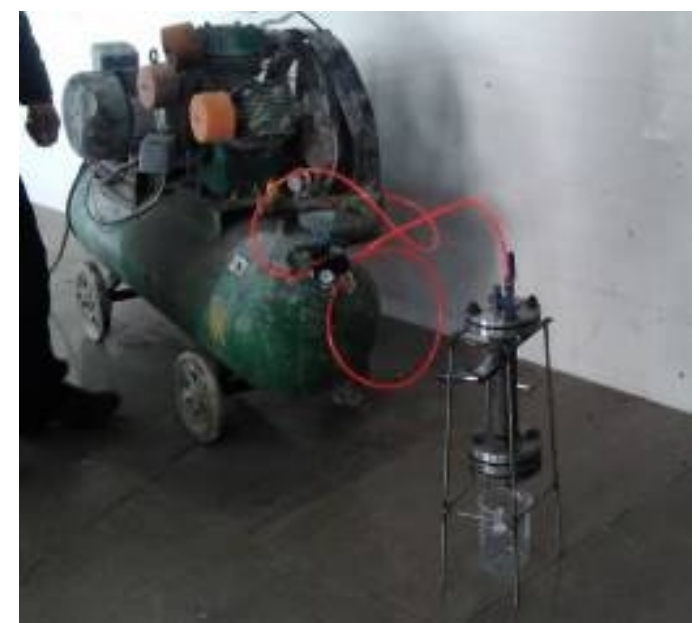

Fig.6 Compressor and anti hydrostatic test device

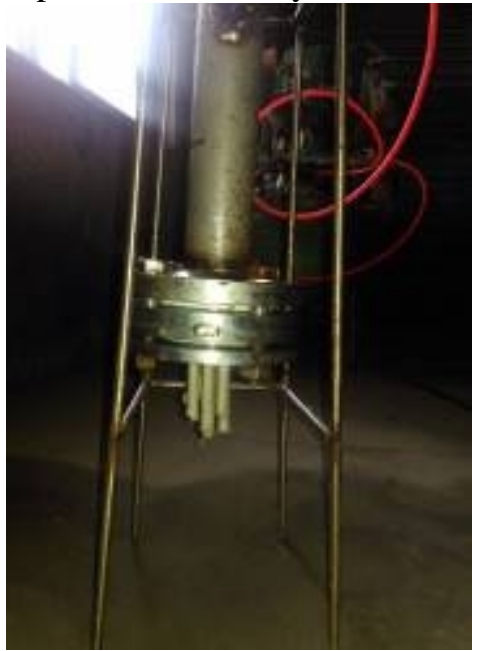

Fig.7 Under pressure, some of the grease is squeezed out 


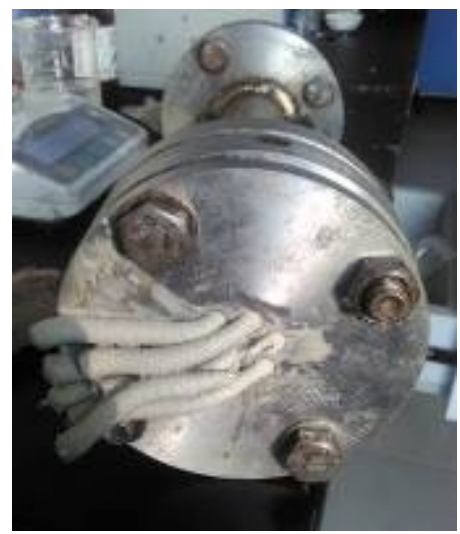

Fig.8 The grease was broken through

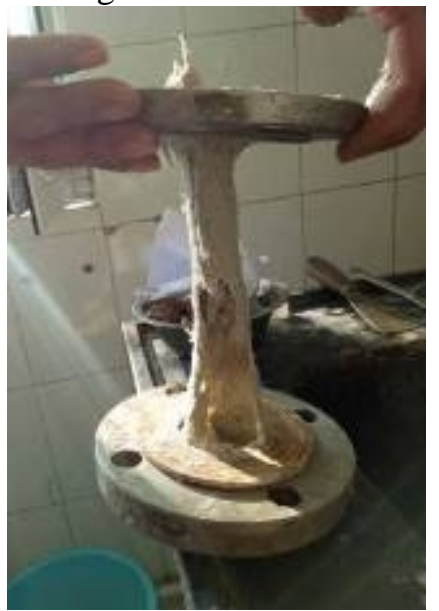

Fig.9 After water immersion and extrusion, the sealing grease still has good stickiness

Water spray test

Because the sealed grease is the main water-proof material at the shield tail, and to prevent the underground water and grouting slurry from entering the shield machine. It is necessary to ensure its good stability under the scouring of the water flow. If grease is not broken up, no softening, decomposition, viscosity decrease shapply through the water spray test, show that the water-proof stability is good.

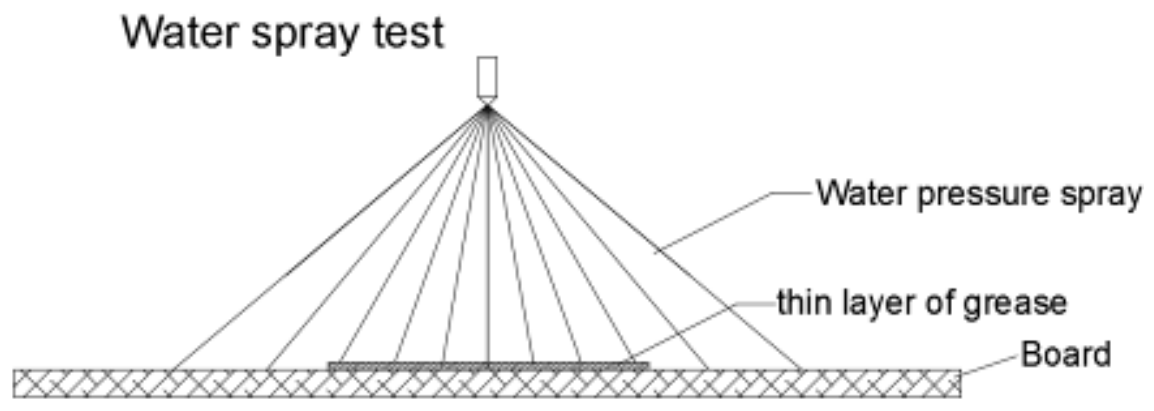

Fig.10 Sketch map of water spray test 


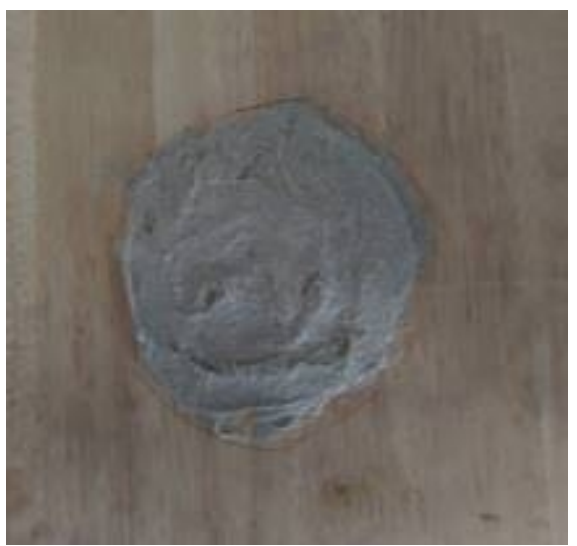

Fig. 11 Apply the sealing grease evenly over the plate

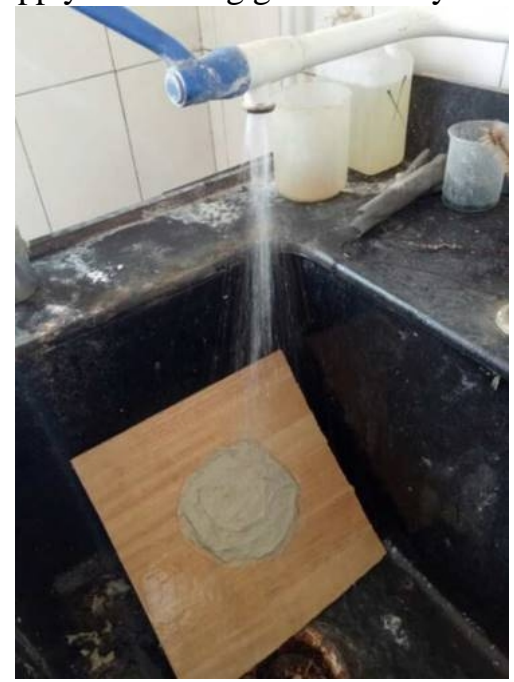

Fig. 12 Observe the condition of the grease under the erosion of the current

\section{Specific gravity test}

Due to the high viscosity of the seal grease, it cannot be measured directly by a densitometer. The stainless steel barrel in penetration test is used to measure the specific gravity of grease.

\section{Test procedure:}

1. Clean the stainless steel barrel and measure the net weight after airing;

2. Add water to the barrel until it is full and the liquid level is horizontal, calculate the volume of the barrel according to the weight of the water in the barrel;

3. Filled the clean barrel with seal grease, in order to avoid empty, the barrel bottom and barrel wall should be smeared firstly, and gradually fill up, the surface of the grease shoud be horizontal;

4. Weighing the barrel and grease quality, calculate grease density.

Need to pay attention to the problem: the viscosity of seal grease is very high and the filling process is likely to be defective and hidden, and repeated measurements are necessary when the difference between maxima and minima is anomalous.

\section{Conclusions}

In the shield project, vigorously implement the concept of energy saving and emission reduction, and realize green construction, has become the focus and difficulty of the project. According to the actual situation of shield construction in China, this study focuses on three technical indexes of grease in shield tail sealing, and summarizes the relevant testing methods with high accuracy and feasibility in construction process. Through the above test method can reasonably and efficiently to shield tail seal grease test, improve the safety and reliability of shield construction, enhance the accuracy of the material receiving inspection, timely identification of unqualified products, to avoid the construction of hysteresis and blindness. 


\section{References}

[1] Yan Zhenlin, Guo Jingbo. Study on evaluation method of grease performance of shield tail seal. Journal of Shijiazhuang Railway University (Natural Science Edition),2010(04).

[2] Wang Deqian . Study on formula and properties of a kind of grease sealed with shield tail . Tunnel construction , 2013(4) : $277-281$

[3] Yan Zhenlin, Guo Jingbo . Study on evaluation method of grease performance of shield tail seal . Journal of Shijiazhuang Railway University(Natural Science Edition), 2010( 2) : 91 -94 .

[4] Wang Deqian . Discussion on anti water pressure, tightness and pumping test of grease for shield tail seal. Tunnel construction , 2014( 2) : $107-110$.

[5] Zhu Zuxi . Shield tail waterproof seal and shield tail sealing grease in Shield Tunneling . Chinese building waterproof , 2009(7): 2 - 6 . 